\title{
The natural extract degalactotigonin exerts antitumor effects on renal cell carcinoma cells through repressing YAP
}

\author{
Yuning Wang ${ }^{1,2 \#}$, Tianyu Hong ${ }^{1,2 \#}$, Linbao Chen ${ }^{1,2 \#}$, Chuanmin $\mathrm{Chu}^{3}$, Jiangbo Zhu ${ }^{4}$, Jing Zhang ${ }^{2}$, \\ Chao Wang ${ }^{2,5}$, Jingcun Zheng ${ }^{1,2}$, Ning Jiang ${ }^{1,2}$, Xingang Cui ${ }^{3}$
}

${ }^{1}$ Ningxia Medical University, Yinchuan, Ningxia, China; ${ }^{2}$ Department of Urinary Surgery, Gongli Hospital, Second Military Medical University (Naval Medical University), Shanghai, China; ${ }^{3}$ Department of Urinary Surgery, The Third Affiliated Hospital of Second Military Medical University (Eastern Hepatobiliary Surgery Hospital), Shanghai, China; ${ }^{4}$ Tai Zhou the First People's Hospital (Wen Zhou Medical University Huangyan Hospital), Taizhou, China; ${ }^{5}$ Department of Urology, the Affiliated Changzhou No. 2 People's Hospital of Nanjing Medical University, Changzhou, China

Contributions: (I) Conception and design: J Zheng, N Jiang, C Wang, X Cui; (II) Administrative support: J Zheng, N Jiang, C Wang, X Cui; (III) Provision of study materials or patients: Y Wang, T Hong, L Chen, C Chu, J Zhu, J Zhang; (IV) Collection and assembly of data: Y Wang, T Hong, L Chen, C Chu, J Zhu, J Zhang; (V) Data analysis and interpretation: All authors; (VI) Manuscript writing: All authors; (VII) Final approval of manuscript: All authors.

"These authors contributed equally to this work.

Correspondence to: Xingang Cui. Department of Urinary Surgery, The Third Affiliated Hospital of Second Military Medical University (Eastern Hepatobiliary Surgery Hospital), 700 North Moyu Road, Shanghai 201805, China. Email: cuixingang@smmu.edu.cn; Ning Jiang. Department of Urinary Surgery, Gongli Hospital, Second Military Medical University, 219 Miaopu Road, Shanghai 200135, China. Email: glyyyb@126.com; Jingcun Zheng. Department of Urinary Surgery, Gongli Hospital, Second Military Medical University, 219 Miaopu Road, Shanghai 200135, China. Email: zhengjingc@sina.com.

Background: The pervasive progression of renal cell carcinoma (RCC) after treatment demands more effective drugs with few side effects. In the present study, we determined whether degalactotigonin (DGT) extracted from Solanum nigrum L. could exert antitumoral effects on RCC and examined the related molecular mechanisms.

Methods: The effects of DGT on RCC cells were assessed by cell counting kit-8 (CCK-8) assay, flow cytometry, invasion and migration assays and subcutaneous tumor xenograft experiments in nude mice. The related molecular mechanisms were delineated by RNA sequencing (RNA-seq), real-time polymerase chain reaction (PCR), western blotting, coimmunoprecipitation (co-IP) and plasmid transfection.

Results: DGT induced apoptosis and suppressed the proliferation, invasion, migration, and tumorigenicity of RCC cells. Mechanistically, yes-associated protein (YAP) signaling was inactivated, and the expression of YAP and its target genes was reduced in degalactotigonin-treated RCC cells. Additionally, DGT activated phosphorylated large tumor suppressor 1/2 (p-LATS1/2) to phosphorylate YAP, which increased YAP retention in the cytoplasm but decreased the amount of YAP that entered the nuclei of RCC cells. Moreover, DGT impaired the increased aggressive features of RCC cells induced by YAP overexpression.

Conclusions: DGT is an effective therapeutic agent, which facilitates the apoptosis and inhibits the proliferation, invasion, migration, and tumorigenicity of RCC cells in a YAP-dependent manner.

Keywords: Renal cell carcinoma (RCC); degalactotigonin; yes-associated protein (YAP); tumor proliferation; tumor progression

Submitted Apr 18, 2020. Accepted for publication Sep 14, 2020.

doi: $10.21037 /$ tcr-20-1864

View this article at: http://dx.doi.org/10.21037/tcr-20-1864 


\section{Introduction}

Renal cell carcinoma (RCC) is the ninth most common malignancy among men worldwide (1) and the sixth and tenth most common malignancy among men and women, respectively, in the United States (2). Surgical treatment serves as the main therapy for RCC patients, and chemotherapy and radiotherapy show limited efficacy (3). Although targeted drugs such as sunitinib have been reported to improve survival in patients with advanced or metastatic RCC, a complete response was limited due to drug resistance in RCC, side effects and the financial burden of treatment, contributing to the progression of RCC and poor patient prognosis (4). Thus, there is a need to search for more effective and less toxic drugs for advanced RCC for use in clinical practice.

Much attention has been placed on the role of natural agents in antitumor therapy due to their low level of side effects $(5,6)$. Among them, Solanum nigrum L. exhibited hepatoprotective effects against $\mathrm{CCl}_{4}$-induced oxidative damage in rats and increased the production of nitric oxide (NO) by recombinant interferon- $\gamma$ (rIFN$\gamma)$-primed macrophages via nuclear factor $\kappa \mathrm{B}(\mathrm{NF}-\kappa \mathrm{B})$ activation $(7,8)$. Furthermore, extracts of $S$. nigrum L. could suppress the growth and progression of various types of tumors, including liver, breast and colon cancers (9-11). Recently, degalactotigonin (DGT), which is extracted from the natural agent $S$. nigrum $\mathrm{L}$., was reported to exert antitumor effects on the growth and metastasis of osteosarcoma through modulation of glycogen synthase kinase $3 \beta$ (GSK3 $\beta$ ) inactivation-mediated repression of the Hedgehog/Gli1 pathway (12). However, the effects of DGT on the growth and progression of RCC have not been elucidated.

The Hippo signaling pathway has been reported to play crucial roles in regulating carcinogenesis and the progression and metastasis of tumors, including RCC $(13,14)$. Among these pathways, the crucial effector yesassociated protein (YAP) is negatively regulated by large tumor suppressor 1/2 (LATS1/2), resulting in the retention of phosphorylated YAP (p-YAP) in the cytoplasm (15). Then, unphosphorylated YAP enters the nucleus, where it serves as a transcription coactivator for transcription factors of the TEA domain transcription factor (TEAD) family to promote the expression of downstream genes that facilitate tumor cell proliferation (16). Moreover, YAP is overexpressed in RCC, and YAP knockdown was shown to inhibit cell proliferation and induce cell cycle arrest and apoptosis (17-19).

In this study, the in vitro and in vivo effects of DGT on RCC cells and the underlying mechanisms of DGT were assessed. Our study suggests that DGT can serve as an efficacious alternative therapeutic agent for advanced RCC.

We present the following article in accordance with the ARRIVE reporting checklist (20) (available at http://dx.doi. org/10.21037/tcr-20-1864).

\section{Methods}

\section{Specific information on degalactotigonin}

DGT was extracted from the plant Solanum nigrum L., a popular medicinal herb in China. DGT $(>90 \%$ purity; molecular weight: $1,035.17 \mathrm{~g} / \mathrm{mol}$; Molecular formula: $\mathrm{C}_{50} \mathrm{H}_{82} \mathrm{O}_{22}$; PubChem Substance ID 329770112), the compound used in the experiments, was purchased from Sigma Aldrich, Co. (St. Louis, MO, USA; catalog No. 39941-51-0).

\section{Cell culture}

The cell lines were bought from the Cell Bank of the Type Culture Collection of the Chinese Academy of Sciences (Shanghai, China) in 2018. A498 and ACHN cells were cultured in minimum essential medium (Gibco, USA) supplemented with fetal bovine serum (FBS, $10 \%$, Gibco). 786-O and OS-RC-2 cells were maintained in Roswell Park Memorial Institute-1640 (RPMI-1640) medium (Gibco) supplemented with FBS. HK-2 cells were maintained in high-glucose Dulbecco's Modified Eagle's Medium (DMEM) (Gibco) supplemented with FBS. The culture media for all cell lines were supplemented with $1 \%$ penicillin/streptomycin (Gibco), and the cell lines were cultured at $37^{\circ} \mathrm{C}$ in $5 \% \mathrm{CO}_{2}$. And the $786-\mathrm{O}$ and A498 cells were chosen as representative RCC cell lines to perform all experiments in this study.

\section{Cell proliferation assays and assessment of apoptosis}

The proliferation of RCC cells under the indicated conditions was evaluated using a cell counting kit-8 (CCK-8) (Dojindo, Japan). The proliferation rates are presented as a proportion compared to the control value, which was obtained from the treatment-free groups. Apoptotic cells were evaluated with Annexin V and Propidium Iodide (PI) staining (Invitrogen, USA) according to the manufacturer's 
instructions and analyzed by flow cytometry with a CyAn ADP sorter (Beckman, USA).

\section{Invasion and migration assays}

Invasion and migration assays were carried out in Transwell chambers (Millipore, USA) with or without Matrigel (BD Biosciences, USA) according to the manufacturer's instructions. The RCC cells were first treated with vehicle or DGT and then collected for migration and invasion assays. A total of $1 \times 10^{4}$ cells per well were plated on inserts without serum and cultured at $37^{\circ} \mathrm{C}$ in the upper chambers. After 36 hours, the cells on the lower surface of the filter were fixed in $4 \%$ paraformaldehyde, stained with $0.5 \%$ crystal violet and examined under a microscope. The average number of migrated cells from five random optical fields (200x magnification) and triplicate filters was determined.

\section{Real-time polymerase chain reaction (PCR)}

RNAiso Plus (9109, Japan) and the PrimeScript One Step RT reagent kit (RR037B, Japan) were used to extract and reverse transcribe RNA. Real-time PCR was performed with SYBR Green Real-Time PCR Master Mix (QPK201, Japan) on an ABI PRISM 7300HT sequence detection system. The results were normalized to expression of the $\beta$-actin gene, and each measurement was performed in triplicate. The fold change relative to the mean value was determined by the $2^{-\Delta \Delta \mathrm{Ct}}$ method. All mRNA sequences of the target genes were obtained through NCBI gene database, and the primers were designed through Primer Premier 6 (Premier, Canada). The specificity of the primers was verified by Primer-BLAST of NCBI. Then all the primers were synthesized by solid phase phosphoamide triester technique and purified by PAGE technique from Shenzhen BGI Technology Services Co. Ltd. (Shenzhen, China). The primer sequences are presented in Figure S1.

\section{Western blot analysis and coimmunoprecipitation (co-IP)}

Cultured cells were lysed in Radio-Immunoprecipitation Assay (RIPA) lysis buffer about $15 \mathrm{~min}$ and then centrifuged at $12,000 \mathrm{~g}$ for $15 \mathrm{~min}$. Protein concentrations were measured using the Pierce BCA Protein Assay Kit (Thermo Scientific, Waltham, MA, USA). Nuclear and cytoplasmic proteins were extracted from the RCC cells using an NEPER Nuclear and Cytoplasmic Extraction Kit (\#78899, Thermo Scientific). Western blot was performed using specific primary antibodies, overnight in the blocking solution at $4{ }^{\circ} \mathrm{C}$. Then membranes were incubated with the corresponding secondary antibody at room temperature for $90 \mathrm{~min}$ and detected using the Amersham Imager 600 (General Electric Company, Fairfield, Connecticut, USA). The following primary antibodies were used: rabbit anti$\beta$-tubulin (\#15115S), anti-Histone H3 (\#4499S), antiYAP (\#14074S), and rabbit anti-YAP (p-S127) (\#13008S) from Cell Signaling Technology (Danvers, USA) and anti-LATS1+LATS2 (ab70565) and anti-LATS1+LATS2 (p-Thr1079+Thr1041) (ab111344) from Abcam (Cambridge, UK). The secondary antibodies used were horse anti-mouse IgG-HRP-linked antibody (\#7076S) and goat anti-rabbit IgG-HRP-linked antibody (\#7074S) from Cell Signaling Technology.

For Co-immunoprecipitation experiments, cell lysates were prepared in the chromatin immunoprecipitation buffer and protein concentrations were measured and incubated with anti-YAP1 antibody (ab52771) (Abcam) or normal Rabbit immunoglobulin G (\#3900S) (Cell Signaling Technology) for 8 hours at $4{ }^{\circ} \mathrm{C}$, followed by addition of Protein A/G Plus-Agarose (Santa Cruz Biotechnology, USA) for another 4 hours. Then Western blotting was applied to examine above samples.

\section{Plasmid transfection}

The YAP plasmid was obtained from Shanghai Integrated Biotech Solutions Co., Ltd. (China). Briefly, DNA fragment of YAP was derived by PCR using platinum Taq polymerase (Invitrogen Life Technologies) with human genomic DNA (Promega) as template. The YAP region was subcloned into the NheI and EcoRI sites of the pcDNA3.1(+) plasmid (Promega) and the plasmid were resistant to ampicillin. Cell transfection with the YAP plasmid was carried out using Lipofectamine 3000 reagent (Invitrogen) according to the manufacturer's protocol, and the sequence of the YAP plasmid is shown in Figure S1.

\section{RNA sequencing (RNA-seq) and data analysis}

Total RNA was purified and quantified. Then, an RNA library was constructed. The distribution of the reads and the alignment quality were estimated using Samtools. From the aligned reads, gene and transcript expression was determined using cufflinks. The differential transcripts were analyzed via cuffdiff. Finally, gene ontology (GO) and pathway functional analyses of the differentially expressed 
transcripts were performed.

\section{Animal experiments and immunobistochemistry (IHC)}

Experiments were performed under a project license (No. 81974391) granted by institutional ethics committee of Second Military Medical University (Shanghai, China), in compliance with the institutional guidelines for the care and use of animals. The animal experiments were performed as reported previously $(21,22)$. Five-week-old male athymic $\mathrm{BALB} / \mathrm{c}$ nude mice (weight 19-22 g) were obtained from Jihui Laboratory Animal Care Co., Ltd. (Shanghai, China) and allowed to acclimate to their new surroundings for one week. All mice were kept in home cages in a specific pathogen-free (SPF) environment with free access to sterilized food and water, and animal experiments were conducted at the Second Military Medical University Animal Experiment Center (Shanghai, China). The home cages were cleaned, and sterilized food and water were exchanged weekly during the experiments. 786-O cells [5 $\times 10^{6}$ cells in $100 \mu \mathrm{L}$ of phosphate buffered saline (PBS)] were injected subcutaneously into the right flank of each nude mouse $(\mathrm{n}=12)$. The mice were randomly divided into 2 groups ( $\mathrm{n}=6 /$ group) 14 days after tumor implantation. All mice in the treatment group were treated with DGT dissolved in the vehicle [dimethyl sulfoxide (DMSO) in water] $(200 \mathrm{mg} / \mathrm{kg})$ every two days by intraperitoneal injection, while mice in the control group were administered vehicle. After treatment, the mouse tumor volumes in each group were measured once a week using a digital caliper [volume $=(\text { width })^{2} \times$ length $\left./ 2\left(\mathrm{~mm}^{3}\right)\right]$. Mice were euthanized 6 weeks after inoculation, and the tumors were removed, fixed in $10 \%$ buffered formalin solution and used for further experiments.

IHC assays were performed with the UltraSensitive SP (Mouse/Rabbit) IHC Kit (Maixin Biotechnologies, China) according to the manufacturer's protocols. Rabbit anti-Ki67 (ab15580, Abcam) was used as the primary antibody. IHC scores for Ki67 staining in each group were calculated as follows: the percentage of positive cells (\% of PPs) and the staining intensity (SI) were determined and multiplied (immunoreactive score, IRS), with a possible IRS values ranging from 0 to 12 . Hematoxylin and eosin (H\&E)-stained sections of ccRCC specimens were evaluated by the pathologist (Y.W.Y., Changhai Hospital) and the IHC results were quantified by two independent investigators (Y.N.W. and T.Y.H) in a double-blinded manner.

\section{Statistical analysis}

All the analyses were performed using GraphPad Prism software (Version 8.2.0). Numerical data are expressed as the mean \pm standard deviation (S.D.) from three independent experiments. Statistical differences between variables were analyzed by two-tailed Student's $t$-test. Differences were considered significant at $\mathrm{P}<0.05$.

\section{Results}

\section{DGT inhibited the proliferation, invasion, and migration and induced the apoptosis of RCC cells}

The chemical structure of DGT (isolated from S. nigrum L, molecular weight, $1,035.17 \mathrm{~g} / \mathrm{mol}$ ) is shown in Figure S2A (23), and the concrete photomicrographs of the cells were presented in Figure 1A. To explore the biological effects of DGT on RCC cells, various RCC cell lines were treated with DGT at different doses for 72 hours. As shown in Figure $1 B$, the half maximal inhibitory concentration (IC50) values ranged from 7.52 to $10.21 \mu \mathrm{mol} / \mathrm{L}$ in the RCC cell lines, which were lower than that in HK-2 cells, suggesting that DGT at the treatment concentration was safe for normal cells. CCK-8 proliferation assays were performed, and the results showed that DGT inhibited the proliferation of 786-O and A498 cells in a dose- and time-dependent manner (Figure 1C). Second, Annexin V/PI double staining demonstrated that degalactotigonin, especially at a $10 \mu \mathrm{mol} / \mathrm{L}$ concentration, increased the number of apoptotic events in 786-O and A498 cells (Figure 1D). In addition, the RCC cells were first treated with DGT or vehicle and then collected for migration and invasion assays. As shown in Figure 1E, the number of 786-O and A498 cells that invaded the Matrigel-coated membranes was reduced with DGT treatment in a dose-dependent manner compared with the number of control untreated cells. Similarly, DGT decreased the number of 786-O and A498 cells that migrated through the membrane in a dose-dependent manner (Figure $1 F$ ). Thus, in vitro assays demonstrate that DGT had inhibitory effects on RCC cells.

\section{DGT suppressed the growth of RCC in vivo}

Pursuant to the in vitro studies described above, we further evaluated the effects of DGT on the growth of RCC cells in vivo. 786-O cells were subcutaneously injected into nude mice, and at two weeks after subcutaneous injection, the mice were randomly divided into two groups 
A

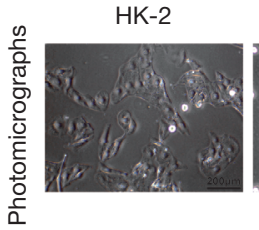

B

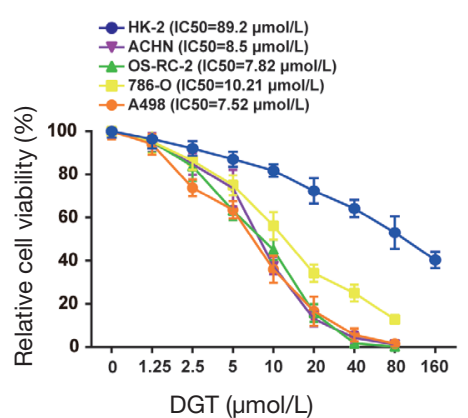

C

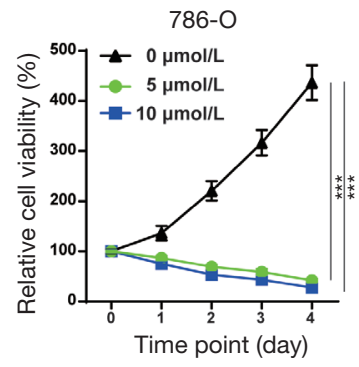

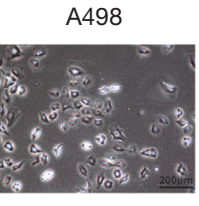

$\mathrm{D}$
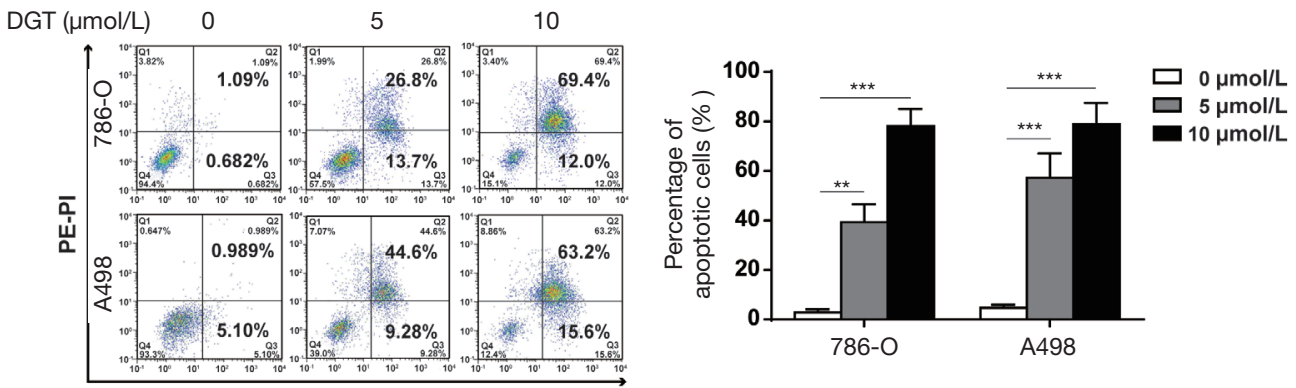

E

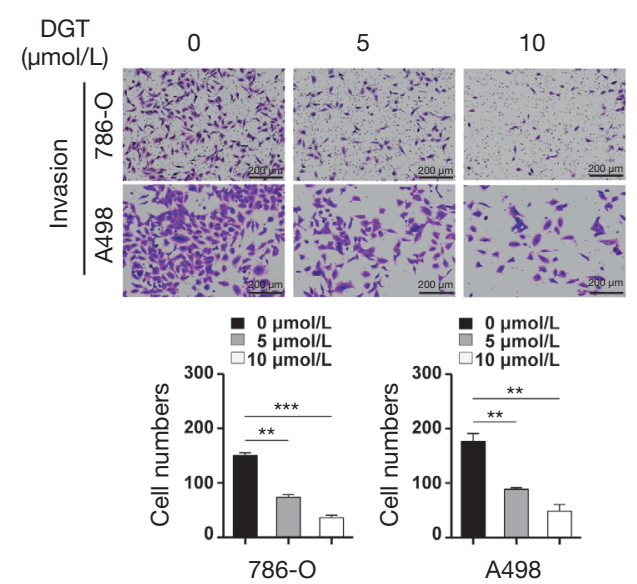

F

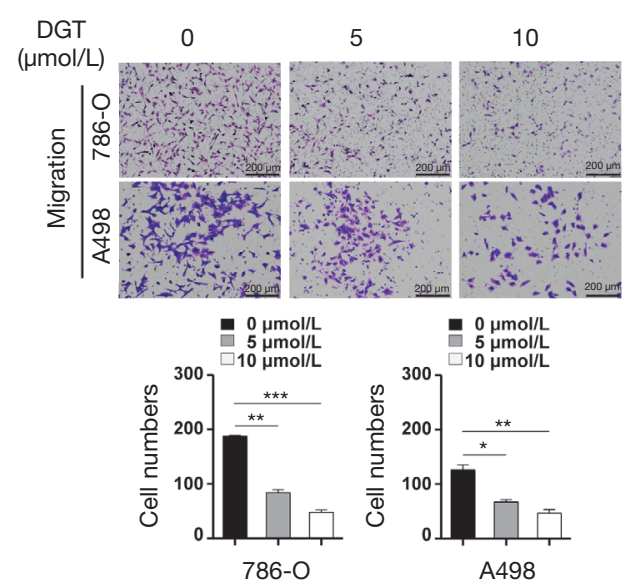

Figure 1 Degalactotigonin inhibited the proliferation, invasion, and migration of renal cell carcinoma (RCC) cells and induced their apoptosis. (A) Photomicrographs of the cells were presented (scale bar $=200 \mu \mathrm{m}$ ). (B) The half maximal inhibitory concentration (IC50) values of degalactotigonin treatment for 72 hours in the HK-2 normal renal cell line and RCC cell lines were calculated. Cells were exposed to degalactotigonin at a range of concentrations for 3 days, and the viability of cells were evaluated using cell counting kit-8 (CCK-8) assays. (C) 786-O and A498 cells were treated with degalactotigonin ( 5 or $10 \mu \mathrm{mol} / \mathrm{L}$ ) for different durations. (D) 786-O and A498 cells were treated with degalactotigonin for 2 days, and Annexin V/Propidium Iodide (PI) staining was performed to analyze the apoptosis of RCC cells via flow cytometry. (E,F) Invasion and migration assays were carried out to investigate the invasion (E) and migration (F) abilities of 786-O and A498 cells treated with or without degalactotigonin for 2 days (scar bar $=200 \mu \mathrm{m}$; stained with $0.5 \%$ crystal violet). All $\mathrm{P}$ values are defined as follows: ${ }^{*}, \mathrm{P}<0.05 ;{ }^{* *}, \mathrm{P}<0.01$ and ${ }^{* * *}, \mathrm{P}<0.001$. 
A

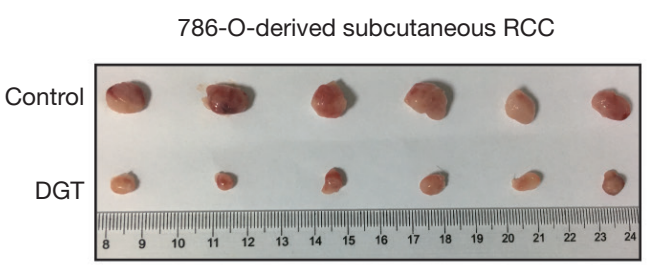

B

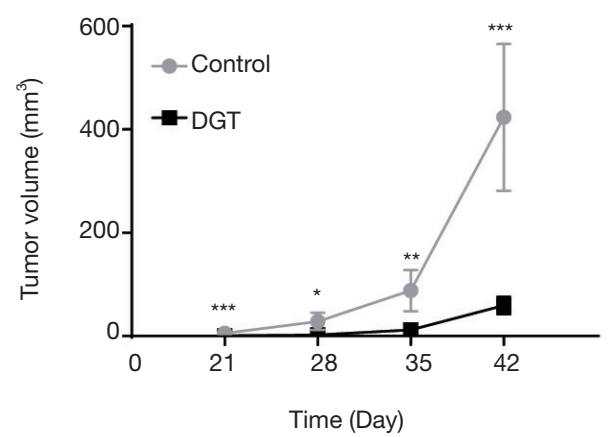

C

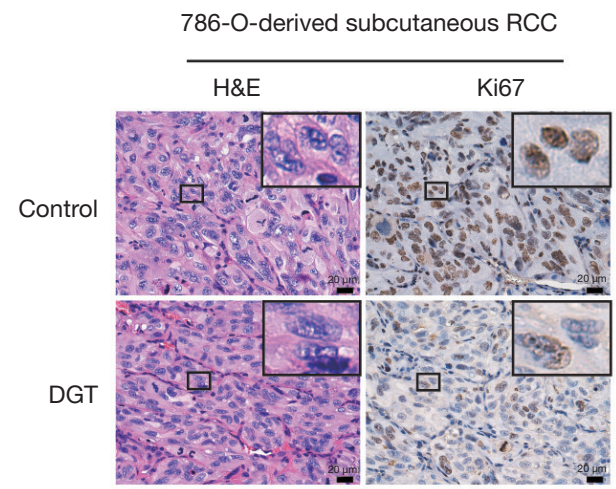

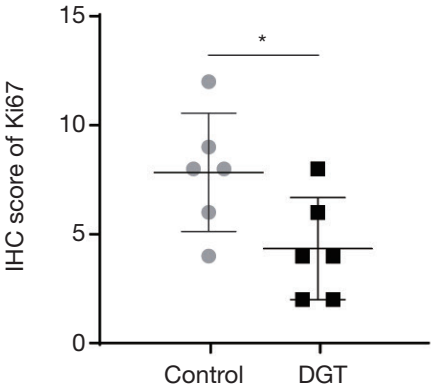

Figure 2 Degalactotigonin suppressed the growth of renal cell carcinoma (RCC) in vivo. (A,B,C) 786-O cells were subcutaneously injected into 6-week nude mice, and after 14 days, the mice were intraperitoneally injected with degalactotigonin (200 mg/kg) or dimethyl sulfoxide (DMSO) in water every two days. Images of 786-O cell-derived xenografts are presented (A), and the tumor volumes in the two groups are compared (B). Tumor specimens were subjected to hematoxylin and eosin (H\&E) and immunohistochemistry (IHC) staining for Ki-67 (C) (scale bar =20 $\mu \mathrm{m})$. All $\mathrm{P}$ values are defined as follows: * $\mathrm{P}<0.05 ;{ }^{* *}, \mathrm{P}<0.01$ and ${ }^{* * *}, \mathrm{P}<0.001$.

and treated with vehicle or DGT $(200 \mathrm{mg} / \mathrm{kg})$ through intraperitoneal injection. As shown in Figure $2 A, B$, the tumors in the degalactotigonin-treated group exhibited inhibited growth and a reduced volume $\left(59.2 \pm 16.7 \mathrm{~mm}^{3}\right)$ compared to that in the untreated control group $\left(423.3 \pm 142.1 \mathrm{~mm}^{3}\right)$. Furthermore, IHC assays demonstrated decreased expression of the proliferation marker Ki67 in degalactotigonin-treated xenografts relative to the control xenografts (Figure 2C). Therefore, DGT had an inhibitory effect on the growth of RCC cells in vivo.

\section{DGT inactivated YAP signaling through facilitating LATS1/2 activation and YAP retention in the cytoplasm of RCC cells}

We next explored the molecular mechanisms by which DGT inhibits the biological processes of RCC cells. First, 786-O cells treated with DGT or vehicle were analyzed by RNA-seq (Figure 3A,B; Figure S2B,C; Tables S1-S3). Among the differentially activated pathways between degalactotigonin-treated and control cells, the Hippo pathway was significantly altered by DGT treatment in RCC cells (Figure 3A; Table S1). Furthermore, we examined the Hippo pathway-related genes among the differentially expressed genes between degalactotigonin-treated and untreated control 786-O cells. As shown in Figure 3B and Table S2, degalactotigonin-treated RCC cells presented downregulated expression of YAP, a crucial effector in the Hippo pathway that facilitates the proliferation and progression of tumors (13). In addition, reduced expression of downstream target genes of YAP, including AMOTL1 and AMOTL2, and increased expression of genes that negatively regulate YAP, including LAST1 and SAV1, were observed in 786-O cells treated with DGT (Figure 3B; Table S2), suggesting that YAP signaling had been inactivated. Moreover, these results were confirmed 
A

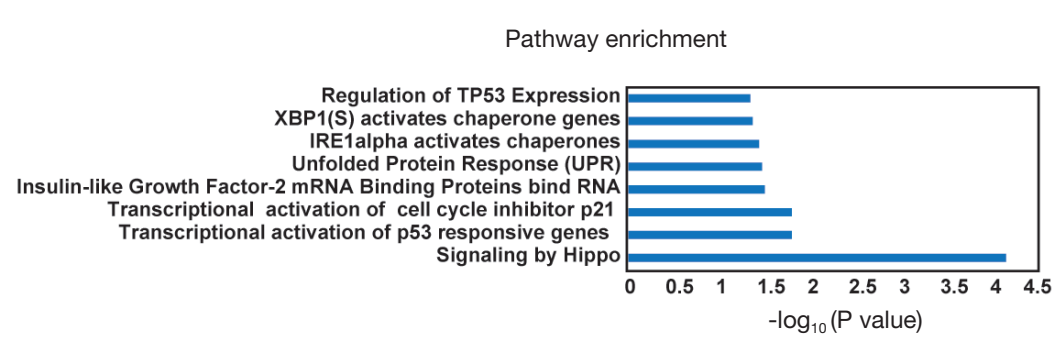

B

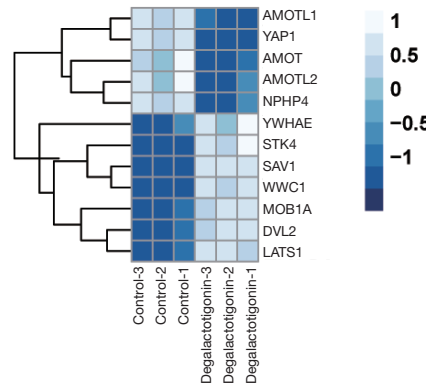

C

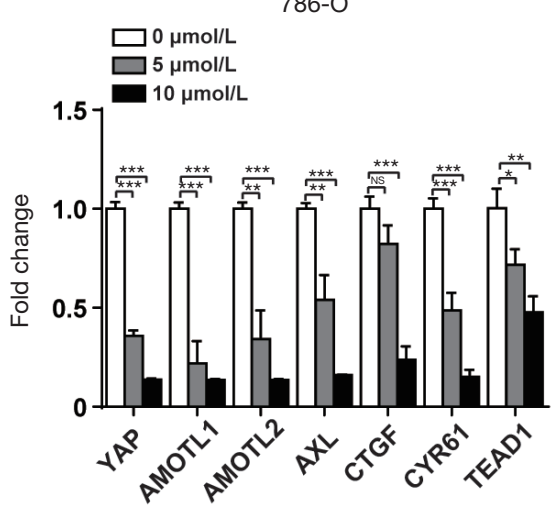

D

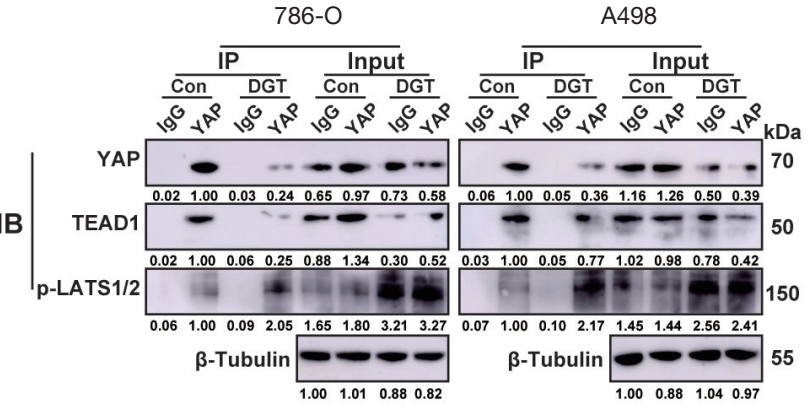

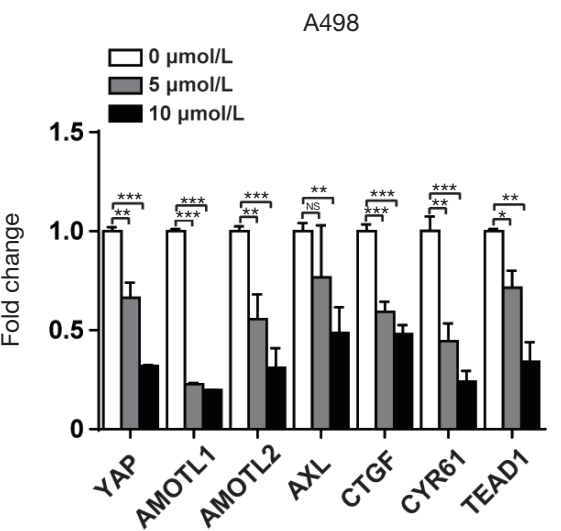

E

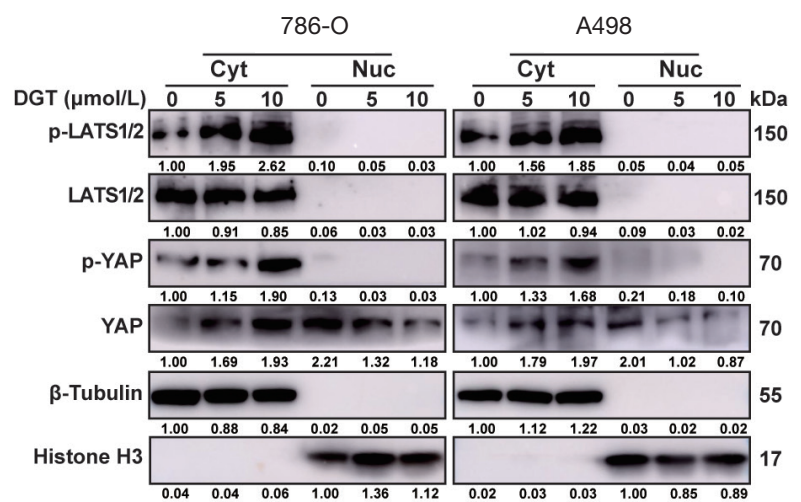

Figure 3 Degalactotigonin inactivated yes-associated protein (YAP) signaling through facilitating large tumor suppressor 1/2 (LATS1/2) activation and YAP retention in the cytoplasm of renal cell carcinoma (RCC) cells. (A) RNA sequencing (RNA-seq) was carried out in 786-O cells treated with or without degalactotigonin. Signaling pathway analysis of differentially expressed genes in degalactotigonin-treated 786-O cells relative to untreated 786O cells. (B) A heatmap depicting the significantly differentially expressed genes between the two groups is shown. (C) The mRNA expression levels of YAP, angiomotin-like protein 1 (AMOTL1), angiomotin-like protein 2 (AMOTL2), AXL receptor tyrosine kinase (AXL), connective tissue growth factor (CTGF), cysteine-rich protein 61 (CYR61) and TEA domain transcription factor 1 (TEAD1) in untreated and degalactotigonin-treated clear cell renal cell carcinoma (ccRCC) cells were examined by real-time polymerase chain reaction (PCR). (D) Western blotting was performed to detect the results of coimmunoprecipitation (co-IP) experiments to precipitate endogenous YAP with TEA domain transcription factor 1 (TEAD1) and phosphorylated large tumor suppressor 1/2 (p-LATS1/2) from untreated and degalactotigonin-treated 786-O and A498 cells. (E) Western blot analysis was used to detect phosphorylated large tumor suppressor 1/2 (p-LATS1/2), large tumor suppressor 1/2 (LATS1/2), phosphorylated yes-associated protein (p-YAP) and YAP in the cytoplasmic and nuclear fractions of untreated and degalactotigonin-treated 786-O and A498 cells. $\beta$-Tubulin and Histone $\mathrm{H} 3$ served as internal controls for the cytoplasmic and nuclear fractions, respectively. All $\mathrm{P}$ values are defined as follows: ${ }^{*}, \mathrm{P}<0.05 ;{ }^{* *}, \mathrm{P}<0.01$ and ${ }^{* * *}, \mathrm{P}<0.001$. 
by real-time PCR, which demonstrated the decreased expression of YAP and its target genes AMOTL1, AMOTL2, AXL, CTGF and CYR61 in 786-O and A498 cells treated with DGT compared with untreated control ells (Figure 3C). Since nuclear YAP is known to recruit TEAD1 to promote the expression of YAP target genes (24), we sought to determine whether DGT affects TEAD1 expression and the recruitment of TEAD 1 by YAP. As expected, the decreased expression of TEAD1 was observed in 786-O and A498 cells treated with degalactotigonin, and a co-IP assay showed the amounts of the YAP and TEAD1 protein complex were decreased in DGT treatment RCC cells (Figure 3C,D), which could suggest why DGT reduced the expression of YAP target genes. These results demonstrate that DGT interrupts YAP-TEAD1 binding, resulting in the reduced expression of YAP target genes in RCC cells.

YAP exerts active protumor effects following its entry into the nucleus, whereas the retention of YAP in the cytoplasm is indicative of an inactive state (16). We thus examined the effect of DGT on the localization of YAP in RCC cells. The nuclear and cytoplasmic fractions were separated, and Western blot assays showed that DGT decreased the level of YAP in the nuclei of 786-O and A498 cells with a concomitant increase in the YAP level in the cytoplasm (Figure 3E). These results indicate that DGT inactivated YAP signaling by promoting YAP retention in the cytoplasm of RCC cells. Moreover, we further determined how DGT inhibits YAP signaling in RCC. Western blot assays showed that degalactotigonin-treated 786-O and A498 cells exhibited upregulated expression of p-LATS1/2 and p-YAP, indicating the retention of activated LATS1/2 and YAP in the cytoplasm of RCC cells (Figure $3 E$ ). In addition, co-IP assays revealed that DGT increased the interaction between p-LATS1/2 and YAP in the cytoplasm of 786-O and A498 cells (Figure 3D). Taken together, these findings show that DGT inactivated YAP signaling through inducing YAP retention in the cytoplasm of RCC cells by activating LATS1/2 via phosphorylation.

\section{DGT impaired the increased growth and progression of RCC cells induced by the ectopic overexpression of YAP}

We next investigated the inhibitory effects of DGT on RCC cells though repressing YAP. 786-O and A498 cells were first transfected with ectopic YAP, which was confirmed by Western blot analysis (Figure $4 A$ ), and the concrete photomicrographs of the cells were presented in Figure $4 B$.
Although CCK-8 proliferation experiments showed that YAP overexpression increased the proliferation of 786-O and A498 cells, DGT treatment inhibited the enhanced proliferation induced by YAP (Figure $4 C$ ). In addition, YAP overexpression blocked the apoptosis of 786-O and A498 cells, but DGT impaired this effect (Figure 4D). Moreover, DGT suppressed the enhanced invasion and migration activities of 786-O and A498 cells induced by YAP overexpression (Figure $4 E, F$ ). Furthermore, the expression of YAP in the nuclear fraction was increased by transfection and DGT inhibited YAP nuclear translocation (Figure 4G). These results indicate that DGT inhibits the aggressive features of RCC cells via YAP.

\section{Discussion}

In the clinic, adjuvant therapies, such as radiotherapy, endocrine therapy, chemotherapy and targeted therapy, are administered to patients with advanced or metastatic tumors, but subsequent side effects usually result in treatment failure and increased mortality (25). Hence, the need for drugs that exhibit strong efficacy with minimal side effects and toxicity is great. In recent years, natural compounds have attracted much attention because of their significant tumoricidal activities against various types of cancers and decreased toxicity in normal tissues compared to that of conventional drugs (26-28). Recently, a multicenter, randomized and controlled phase IV clinical trial demonstrated that Huaier granules serve as an effective adjuvant therapy for hepatocellular carcinoma (HCC) after curative liver resection, improving the recurrence-free and overall survival of HCC patients (29). Thus, extracts derived from natural sources deserve more attention, and further studies are needed to elucidate their antitumor effects and related mechanisms.

Given that chemotherapy and radiotherapy exhibit little efficacy against advanced or metastatic RCC, targeted drugs, such as sunitinib serve as the mainstay treatment (4). However, most RCCs still progress and metastasize even after targeted therapy. In the present study, we first demonstrate that degalactotigonin, an extract derived from a natural source, promoted the apoptosis and inhibited the proliferation, invasion, and migration of RCC cells in vitro. Furthermore, DGT strongly suppressed the growth of RCC in vivo (Figure $4 H$ ). Therefore, DGT may be a candidate agent for the treatment of advanced tumors in clinical practice. In fact, DGT is an extract from S. nigrum L., a traditional Chinese medicine. S. nigrum L. could ameliorate 
A

B
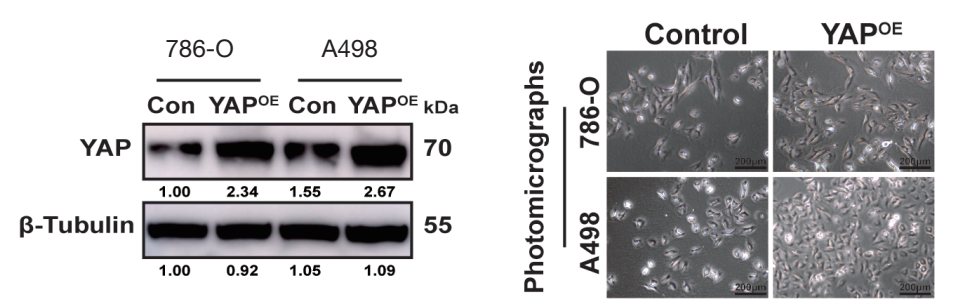

D

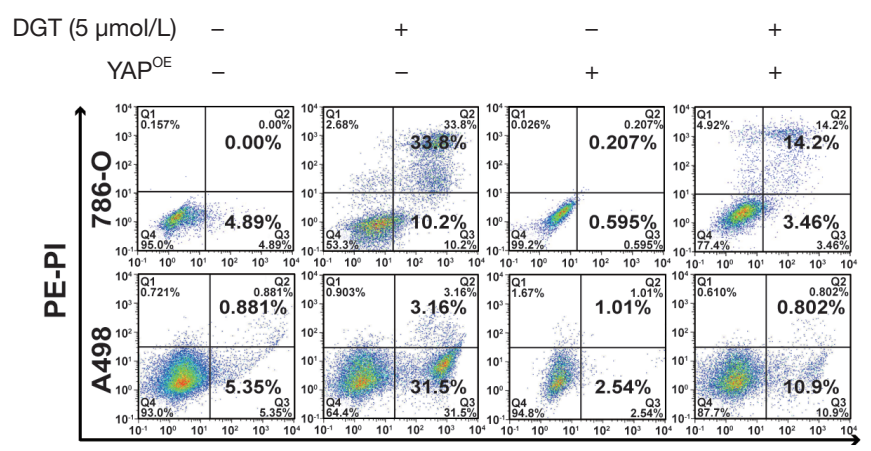

FITC-Annexin V

$E$

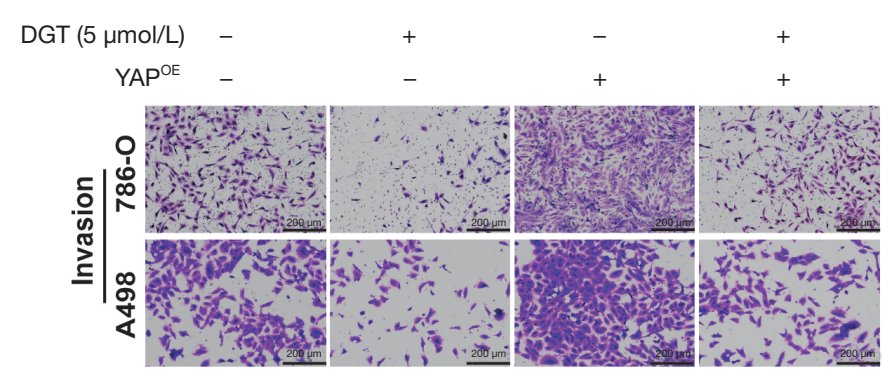

$\mathrm{F}$

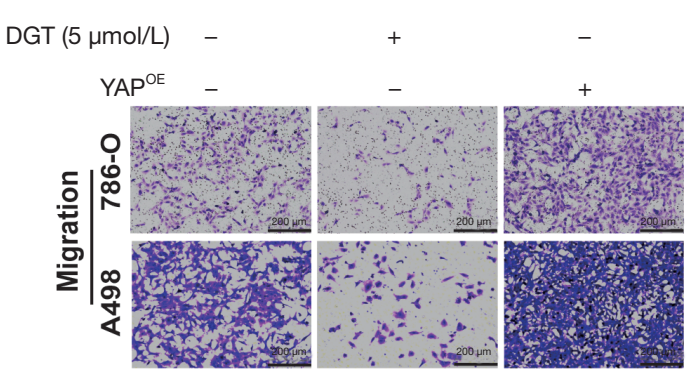

C

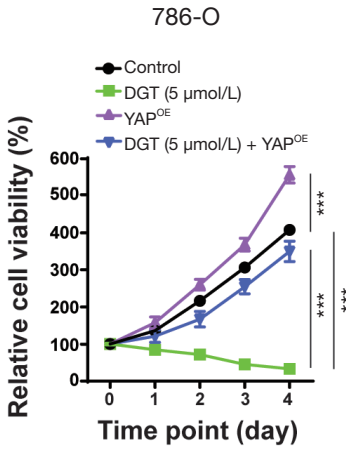

A498

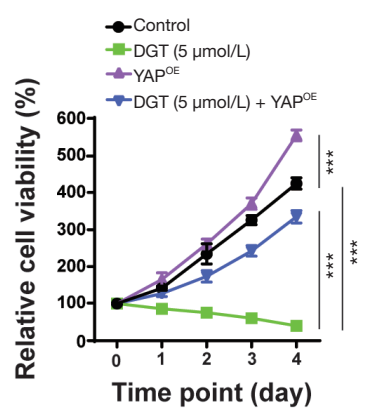

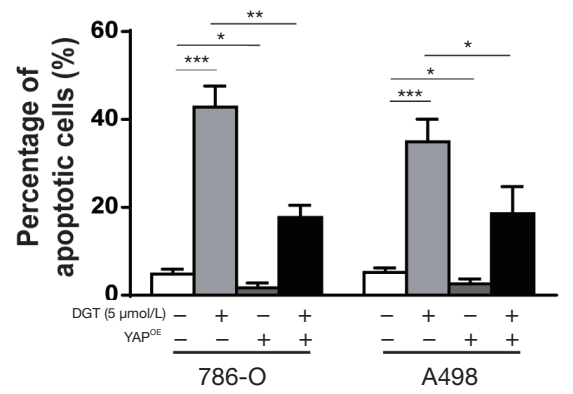
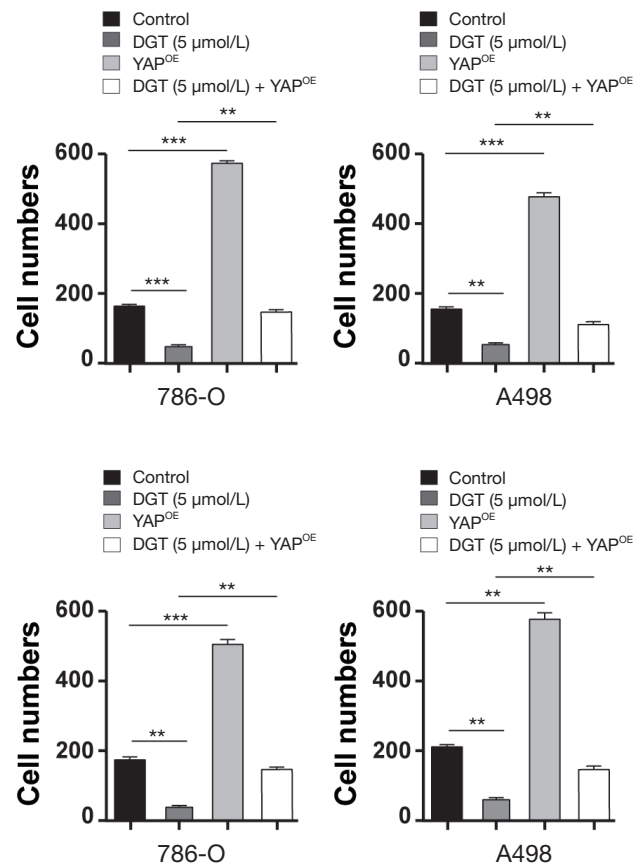
G

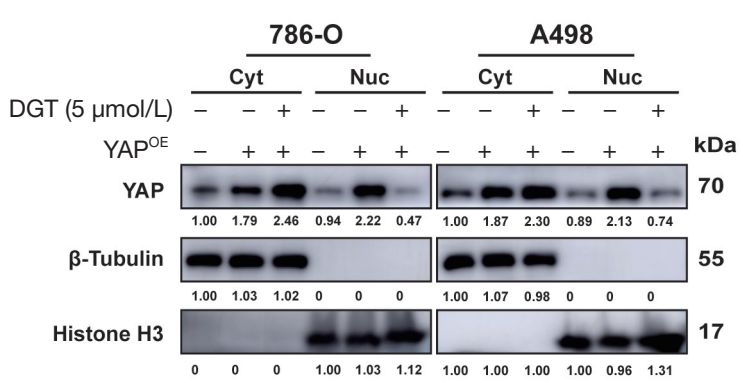

$\mathrm{H}$

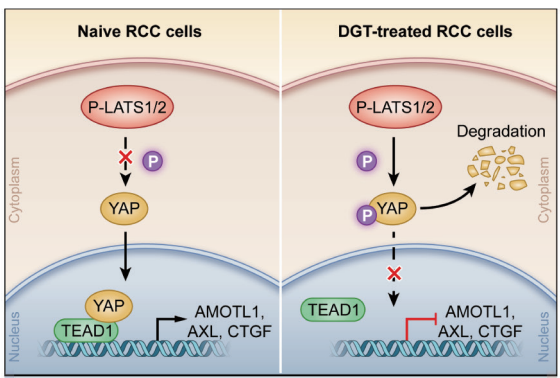

Figure 4 Degalactotigonin impaired the increased growth and progression of renal cell carcinoma (RCC) cells induced by ectopic overexpression of yes-associated protein (YAP). (A) Western blot analysis of YAP in 786-O and A498 cells with or without YAP overexpression. (B) Photomicrographs of the cells were presented (scale bar $=200 \mu \mathrm{m}$ ). (C) The viability of 786-O and A498 cells with or without YAP overexpression that were treated with or without degalactotigonin $(5 \mu \mathrm{mol} / \mathrm{L}$ ) for different durations was detected using cell counting kit-8 (CCK-8) assays. (D) 786-O and A498 cells with or without YAP overexpression that were treated without or with degalactotigonin $(5 \mu \mathrm{mol} / \mathrm{L})$ for 2 days were subjected to Annexin V/Propidium Iodide (PI) staining to analyze the apoptosis of RCC cells via flow cytometry. (E,F) Invasion (E) and migration (F) assays were carried out to investigate the invasion ability of 786-O or A498 cells with or without YAP overexpression that were treated without or with degalactotigonin $(5 \mu \mathrm{mol} / \mathrm{L})(\mathrm{scale}$ bar $=200 \mu \mathrm{m}$, stained with $0.5 \%$ crystal violet). (G) Western blot analysis was used to detect YAP in the cytoplasmic and nuclear fractions of 786-O or A498 cells with or without YAP overexpression that were treated without or with degalactotigonin ( $5 \mu \mathrm{mol} / \mathrm{L})$. $\beta$-Tubulin and Histone $\mathrm{H} 3$ served as internal controls for the cytoplasmic and nuclear fractions, respectively. (H) Schematic diagram of the underlying mechanisms described in our study. All $\mathrm{P}$ values are defined as follows: *, $\mathrm{P}<0.05$; **, $\mathrm{P}<0.01$ and ${ }^{* * *}, \mathrm{P}<0.001$.

scopolamine-induced cognitive and neurochemical impairments in rats and inhibit spore germination of Alternaria brassicicola (30,31). Although S. nigrum L. has been reported to inhibit some tumors, such as breast cancer, HCC and osteosarcoma, its antitumor effects against RCC remain unknown $(10,12,32)$.

YAP, a downstream effector of the Hippo pathway, has been investigated for its role in mammalian development, cellular differentiation and tumorigenesis $(33,34)$. YAP is required for the growth of RCC and the stem-like properties of cancer stem cells in RCC (18). Consistent with these roles, we found that YAP overexpression enhanced proliferation. We also demonstrated that YAP promoted invasion and migration and inhibited apoptosis in RCC cells. Although other studies have shown that DGT regulates the Hedgehog/Gli1 and AKT/mTOR pathways (12), the effect of DGT on the Hippo pathway in tumors has not been reported. Our study is the first to demonstrate via RNA-seq the reduced expression of downstream target genes of YAP and increased expression of genes that negatively regulate YAP, such as LAST1 and SAV1, in 786-O cells treated with degalactotigonin. Moreover, we found that DGT impaired the increased growth of RCC induced by ectopic overexpression of YAP in vitro and in vivo. Furthermore, we established that DGT inhibits the mRNA expression of YAP and decreases the expression of YAP target genes by blocking the interaction between YAP and TEAD1, which is normally bound to the promoters of YAP target genes to facilitate their transcription. In addition, DGT destabilizes YAP by activating LAST1/2, resulting in the retention of YAP in the cytoplasm. As an essential next step towards the clinical application degalactotigonin, we will evaluate its effects on the progression and sunitinib resistance of patient-derived xenografts (PDXs) and assess its effects and safety in the clinic.

\section{Conclusions}

DGT can serve as a viable and effective therapeutic agent for advanced RCC.

\section{Acknowledgments}

Funding: This work was supported by the following funding sources (eight in total): The Top-level Clinical Discipline Project of Shanghai Pudong (PWYgf2018-03), National Natural Science Foundation of China (No. 81773154, 81772747, 81974391), Pudong New Area Science and technology development fund special fund for people's livelihood Research (medical and health) (PKJ2019-Y19), the Program of Shanghai Academic/Technology Research Leader (No. 19XD1405100), Shanghai Natural Science 
Foundation (19ZR1447200), the Shanghai "Rising Stars of Medical Talent" Youth Development Program: Outstanding Youth Medical Talents (X Cui), Meng Chao Talent Training Program-Cultivation of Leading Talents Reserve (X Cui), and the Shanghai Medical Guidance (Chinese and Western Medicine) Science and Technology Support Project (No. 17411960200). The funders had role in study design, data analysis, decision to publish, or preparation of the manuscript. We also thank Shanghai BioGenius biotech. Co., Ltd. (China) for his BioGenius Cloud Computing Service and bioinformatics analysis.

\section{Footnote}

Reporting Checklist: The authors have completed the ARRIVE reporting checklist. Available at http://dx.doi. org/10.21037/tcr-20-1864

Data Sharing Statement: Available at http://dx.doi. org/10.21037/tcr-20-1864

Conflicts of Interest: All authors have completed the ICMJE uniform disclosure form (available at http://dx.doi. org/10.21037/tcr-20-1864). The authors have no conflicts of interest to declare.

Ethical Statement: The authors are accountable for all aspects of the work in ensuring that questions related to the accuracy or integrity of any part of the work are appropriately investigated and resolved. Experiments were performed under a project license (No. 81974391) granted by institutional ethics committee of Second Military Medical University (Shanghai, China), in compliance with the institutional guidelines for the care and use of animals.

Open Access Statement: This is an Open Access article distributed in accordance with the Creative Commons Attribution-NonCommercial-NoDerivs 4.0 International License (CC BY-NC-ND 4.0), which permits the noncommercial replication and distribution of the article with the strict proviso that no changes or edits are made and the original work is properly cited (including links to both the formal publication through the relevant DOI and the license). See: https://creativecommons.org/licenses/by-nc-nd/4.0/.

\section{References}

1. Torre LA, Bray F, Siegel RL, et al. Global Cancer
Statistics, 2012. CA Cancer J Clin 2015;65:87-108.

2. Siegel RL, Miller KD, Jemal A. Cancer statistics, 2018. CA Cancer J Clin 2018;68:7-30.

3. Hsieh JJ, Purdue MP, Signoretti S, et al. Renal cell carcinoma. Nat Rev Dis Primers 2017;3:17009.

4. Posadas EM, Limvorasak S, Figlin RA. Targeted therapies for renal cell carcinoma. Nat Rev Nephrol 2017;13:496-511.

5. Mukhtar E, Adhami VM, Mukhtar H. Targeting microtubules by natural agents for cancer therapy. Mol Cancer Ther 2014;13:275-84.

6. von Schwarzenberg K, Vollmar AM. Targeting apoptosis pathways by natural compounds in cancer: marine compounds as lead structures and chemical tools for cancer therapy. Cancer Lett 2013;332:295-303.

7. Lin HM, Tseng HC, Wang CJ, et al. Hepatoprotective effects of Solanum nigrum Linn extract against $\mathrm{CCl}(4)$ induced oxidative damage in rats. Chem Biol Interact 2008;171:283-93.

8. An HJ, Kwon KB, Cho HI, et al. Solanum nigrum produces nitric oxide via nuclear factor-kappaB activation in mouse peritoneal macrophages. Eur J Cancer Prev 2005; 14:345-50.

9. Ding X, Zhu FS, Li M, et al. Induction of apoptosis in human hepatoma SMMC-7721 cells by solamargine from Solanum nigrum L. J Ethnopharmacol 2012;139:599-604.

10. Son YO, Kim J, Lim JC, et al. Ripe fruit of Solanum nigrum L. inhibits cell growth and induces apoptosis in MCF-7 cells. Food Chem Toxicol 2003;41:1421-8.

11. Yu C, Liu SL, Qi MH, et al. Herbal medicine Guan Chang Fu Fang enhances 5-fluorouracil cytotoxicity and affects drug-associated genes in human colorectal carcinoma cells. Oncol Lett 2015;9:701-8.

12. Zhao Z, Jia Q, Wu MS, et al. Degalactotigonin, a Natural Compound from Solanum nigrum L., Inhibits Growth and Metastasis of Osteosarcoma through GSK3 InactivationMediated Repression of the Hedgehog/Gli1 Pathway. Clin Cancer Res 2018;24:130-44.

13. Gill MK, Christova T, Zhang YY, et al. A feed forward loop enforces YAP/TAZ signaling during tumorigenesis. Nat Commun 2018;9:3510.

14. Liu S, Yang Y, Wang W, et al. Long noncoding RNA TUG1 promotes cell proliferation and migration of renal cell carcinoma via regulation of YAP. J Cell Biochem 2018;119:9694-706.

15. Chen M, Wu L, Tu J, et al. miR-590-5p suppresses hepatocellular carcinoma chemoresistance by targeting YAP1 expression. EBioMedicine 2018;35:142-54.

16. Wu LMN, Deng Y, Wang J, et al. Programming of 
Schwann Cells by Lats1/2-TAZ/YAP Signaling Drives Malignant Peripheral Nerve Sheath Tumorigenesis. Cancer Cell 2018;33:292-308.e7.

17. Cao JJ, Zhao XM, Wang DL, et al. YAP is overexpressed in clear cell renal cell carcinoma and its knockdown reduces cell proliferation and induces cell cycle arrest and apoptosis. Oncol Rep 2014;32:1594-600.

18. Qu L, Wu Z, Li Y, et al. A feed-forward loop between lncARSR and YAP activity promotes expansion of renal tumour-initiating cells. Nat Commun 2016;7:12692.

19. Lei C, Lv S, Wang H, et al. Leukemia Inhibitory Factor Receptor Suppresses the Metastasis of Clear Cell Renal Cell Carcinoma Throuulatigh Negative Regon of the YesAssociated Protein. Dna Cell Biol 2018;37:659-69.

20. Kilkenny C, Browne WJ, Cuthill IC, et al. Improving Bioscience Research Reporting: The ARRIVE Guidelines for Reporting Animal Research. PLoS Biol 2010;8:e1000412.

21. Cheng R, Li N, Yang S, et al. Long non-coding RNA ZEB1-AS1 promotes cell invasion and epithelial to mesenchymal transition through inducing ZEB1 expression in cervical cancer. Onco Targets Ther 2018;11:7245-53.

22. Cao Q, Lu W, Zhou T, et al. Analgesic-antitumor peptide inhibits angiogenesis by suppressing AKT activation in hepatocellular carcinoma. Mol Cell Biochem 2019;455:119-25.

23. National Center for Biotechnology Information. PubChem Database. Source=Sigma-Aldrich, SID=329770112, Available online: https://pubchem.ncbi.nlm.nih.gov/ substance/329770112

24. Kim T, Hwang D, Lee D, et al. MRTF potentiates TEADYAP transcriptional activity causing metastasis. EMBO J 2017;36:520-35.

25. Choueiri TK, Motzer RJ. Systemic Therapy for Metastatic
Renal-Cell Carcinoma. N Engl J Med 2017;376:354-66.

26. Shi H, Shi D, Wu Y, et al. Qigesan inhibits migration and invasion of esophageal cancer cells via inducing connexin expression and enhancing gap junction function. Cancer Lett 2016;380:184-90.

27. Parekh HS, Liu G, Wei MQ. A new dawn for the use of traditional Chinese medicine in cancer therapy. Mol Cancer 2009;8:21.

28. Liu Y, Cao W, Zhang B, et al. The natural compound magnolol inhibits invasion and exhibits potential in human breast cancer therapy. Sci Rep 2013;3:3098.

29. Chen Q, Shu C, Laurence AD, et al. Effect of Huaier granule on recurrence after curative resection of HCC: a multicentre, randomised clinical trial. Gut 2018;67:2006-16.

30. Ogunsuyi OB, Ademiluyi AO, Oboh G, et al. Green leafy vegetables from two Solanum spp. (Solanum nigrum $\mathrm{L}$ and Solanum macrocarpon L) ameliorate scopolamine-induced cognitive and neurochemical impairments in rats. Food Sci Nutr 2018;6:860-70.

31. Lin TC, Fan MC, Wang SY, et al. Identification of the Solanum nigrum extract component involved in controlling cabbage black leaf spot disease. J Agric Food Chem 2011;59:1667-72.

32. Yang MY, Hung CH, Chang $\mathrm{CH}$, et al. Solanum nigrum Suppress Angiogenesis-Mediated Tumor Growth Through Inhibition of the AKT/mTOR Pathway. Am J Chin Med 2016;44:1273-88.

33. Han H, Qi R, Zhou JJ, et al. Regulation of the Hippo Pathway by Phosphatidic Acid-Mediated Lipid-Protein Interaction. Mol Cell 2018;72:328-40.e8.

34. Mach J, Atkins M, Gajewski KM, et al. Modulation of the Hippo pathway and organ growth by RNA processing proteins. Proc Natl Acad Sci U S A 2018;115:10684-9.
Cite this article as: Wang Y, Hong T, Chen L, Chu C, Zhu J, Zhang J, Wang C, Zheng J, Jiang N, Cui X. The natural extract degalactotigonin exerts antitumor effects on renal cell carcinoma cells through repressing YAP. Transl Cancer Res 2020;9(12):7550-7561. doi: 10.21037/tcr-20-1864 
Supplementary

\begin{tabular}{|c|c|c|}
\hline Name & Forward primer & Reverse primer \\
\hline YAP & 5'-TAGCCCTGCGTAGCCAGTTA-3' & 5'-TCATGCTTAGTCCACTGTCTGT-3' \\
\hline AMOTL1 & 5'-CCATGAATGCCGCAGCCACT-3' & 5'-АССTССTCСTCСTCTTGCCAGA-3' \\
\hline AMOTL2 & 5'- AAGTCGGTGCCATCTGTT-3' & 5'- GGTGCTCTGTCTGTAGTCA-3' \\
\hline AXL & 5'-CGCTGCCTGTGTCCTCATCTTG -3' & 5'-TCAGTGGTCCGACGACTGTAGG -3 \\
\hline CTGF & 5'-ACCGACTGGAAGACACGTTTG-3' & 5'-CCAGGTCAGCTTCGCAAGG-3' \\
\hline CYR61 & 5'-TTGGAATGGAGCCTCGCATCCT-3' & 5'-AAGGCGGCACTCAGGGTTGT-3' \\
\hline TEAD1 & 5'-GGCCCTGGCTATCTATCCACCA-3' & 5'-CCTCGTCTTGCCTGTCCTGAGT-3' \\
\hline $\boldsymbol{\beta}$-actin & 5'-CCCTGGCACCCAGCAC-3' & 5'-GCCGATCCACACGGAG-3' \\
\hline
\end{tabular}

YAP, yes-associated protein; AMOTL1, angiomotin-like protein 1; AMOTL2, angiomotin-like protein 2; AXL, AXL receptor tyrosine kinas; CTGF, connective tissue growth factor; CYR61, cysteine-rich protein 61; TEAD1, TEA domain transcription factor 1.

\begin{tabular}{|c|c|}
\hline & $\mathrm{YAP}^{\mathrm{OE}}$-plasmid sequence \\
\hline YAP $^{\mathrm{OE}}$ & $\begin{array}{l}\text { ATGGATCCCGGGCAGCAGCCGCCGCCTCAACCGGCCCCCCAGGGCCAAGGGCAGCCGCCTTCGCAGCCCCCGCAGGGGC } \\
\text { AGGGCCCGCCGTCCGGACCCGGGCAACCGGCACCCGCGGCGACCCAGGCGGCGCCGCAGGCACCCCCCGCCGGGCATC } \\
\text { AGATCGTGCACGTCCGCGGGGACTCGGAGACCGACCTGGAGGCGCTCTTCAACGCCGTCATGAACCCCAAGACGGCCAACG } \\
\text { TGCCCCAGACCGTGCCCATGAGGCTCCGGAAGCTGCCCGACTCCTCTTCAAGCCGCCGGAGCCCAATCCCACTCCCGAC } \\
\text { AGGCCAGTACTGATGCAGGCACTGCAGGAGCCCTGACTCCACAGCATGTTCGAGCTCATTCCTCTCCAGCTTCTCTGCAGTTG } \\
\text { GGAGCTGTTCTCCTGGGACACTGACCCCACTGGAGTAGTCTCTGGCCCAGCAGCTACACCCACAGCTCAGCATCTTCGAC } \\
\text { AGTCTTCTITGAGATACCTGATGATGTACCTCTGCCAGCAGGTTGGGAGATGGCAAAGACATCTTCTGGTCAGAGATACTTCTTA } \\
\text { AATCACATCGATCAGACAACAACATGGCAGGACCCCAGGAAGGCCATGCTGTCCCAGATGAACGTCACAGCCCCCACCAGTC } \\
\text { CACCAGTGCAGCAGAATATGATGAACTCGGCTTCAGCCATGAACCAGAGAATCAGTCAGAGTGCTCCAGTGAAACAGCCACCA } \\
\text { CCCCTGGCTCCCCAGAGCCCACAGGGAGGCGTCATGGGTGGCAGCAACTCCAACCAGCAGCAACAGATGCGACTGCAGCAA } \\
\text { CTGCAGATGGAGAAGGAGAGGCTGCGGCTGAAACAGCAAGAACTGCTTCGGCAGGAGTTAGCCCTGCGTAGCCAGTACCAA } \\
\text { CACTGGAGCAGGATGGTGGGACTCAAAATCCAGTGTCTTCTCCCGGGATGTCTCAGGAATTGAGAACAATGACGACCAATAGCT } \\
\text { CAGATCCTTCCTTAACAGTGGCACCTATCACTCTCGAGATGAGAGTACAGACAGTGGACTAAGCATGAGCAGCTACAGTGTCC } \\
\text { CTCGAACCCCAGATGACTTCCTGAACAGTGTGGATGAGATGGATACAGGTGATACTATCAACCAAAGCACCCTGCCCTCACAGC } \\
\text { AGAACCGTTTCCCAGACTACCTTGAAGCCATTCCTGGGACAAATGTGGACCTTGGAACACTGGAAGGAGATGGAATGAACATAG } \\
\text { AAGGAGAGGAGCTGATGCCAAGTCTGCAGGAAGCTTTGAGTTCTGACATCCTTAATGACATGGAGTCTGTTTGGCTGCCACCA } \\
\text { AGCTAGATAAAGAAAGCTTTTTACATGGTATAG }\end{array}$ \\
\hline
\end{tabular}

YAP ${ }^{O E}$, yes-associated protein (YAP) overexpression.

Figure S1 Primer and plasmid sequences. 
A

\section{Chemical Structure of Degalactotigonin}

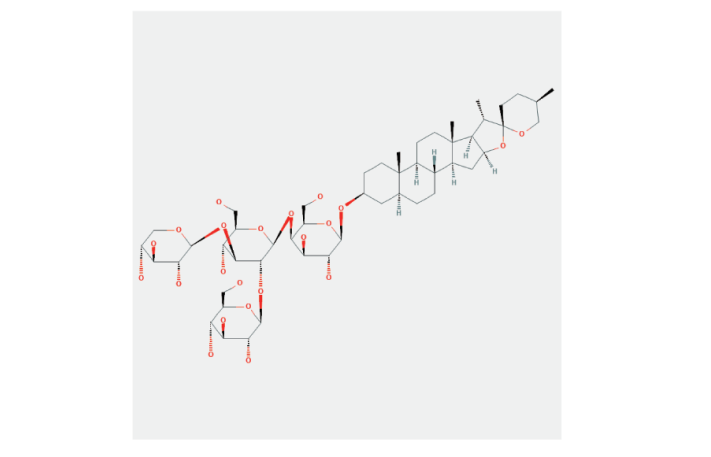

National Center for Biotechnology Information. PubChem Database. Source=SigmaAldrich, SID=329770112, https://pubchem.ncbi.nlm.nih.gov/substance/329770112.)

B

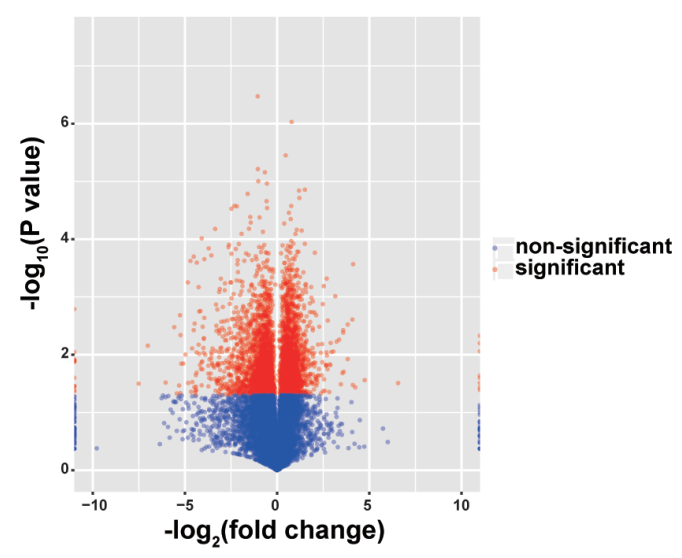

C

Go enrichment

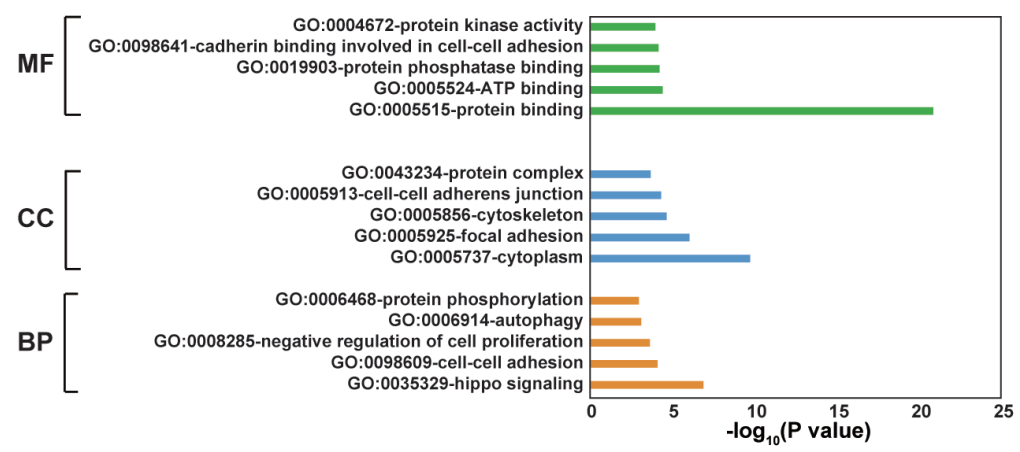

Figure S2 (A) The chemical structure of degalactotigonin is presented (available at the website https://pubchem.ncbi.nlm.nih.gov/ substance/329770112). (B) Scatter plot of significantly differentially expressed genes in 786-O cells with or without degalactotigonin treatment. (C) Gene ontology (GO) analysis was used to classify differentially expressed genes in 786-O cells with or without degalactotigonin treatment. 
Table S1 Signaling pathway analysis of significantly differentially expressed genes in control or degalactotigonin (DGT) treated 786-O cells

\begin{tabular}{|c|c|c|c|}
\hline Pathway identifier & Pathway name & $\#-\log 10(P)$ & Entities $P$ value \\
\hline R-HSA-69560 & Transcriptional activation of p53 responsive genes & 1.796568943 & 0.015974639 \\
\hline R-HSA-69895 & Transcriptional activation of cell cycle inhibitor p21 & 1.796568943 & 0.015974639 \\
\hline R-HSA-428359 & $\begin{array}{l}\text { Insulin-like growth factor-2 mRNA binding proteins (IGF2BPs/IMPs/ } \\
\qquad \text { VICKZs) bind RNA }\end{array}$ & 1.500466138 & 0.031588853 \\
\hline R-HSA-381070 & IRE1alpha activates chaperones & 1.439299463 & 0.036366419 \\
\hline R-HSA-381038 & XBP1 (S) activates chaperone genes & 1.369382435 & 0.042718654 \\
\hline R-HSA-6804754 & Regulation of TP53 expression & 1.343186 & 0.045374724 \\
\hline
\end{tabular}

R, Reactome; HSA, Homo sapiens. 
Table S2 Significantly differentially expressed genes in control and degalactotigonin (DGT) treated 786-O cells

\begin{tabular}{lcccccccc}
\hline Gene & Control-1 & Control-2 & Control-3 & DGT-1 & DGT-2 & DGT-3 & P value & Fold change \\
\hline AMOT & 2.29211 & 1.36983 & 1.79556 & 0.712478 & 0.523156 & 0.481717 & 0.035449 & 0.314677 \\
AMOTL1 & 51.26012 & 45.809 & 52.51294 & 30.82607 & 29.53478 & 32.32062 & 0.005641 & 0.619603 \\
AMOTL2 & 25.0911 & 19.8289 & 22.3164 & 14.8918 & 10.8842 & 10.6842 & 0.007631 & 0.542269 \\
DVL2 & 10.0039 & 9.79907 & 9.2591 & 13.263 & 13.5092 & 13.0765 & 0.00059 & 1.371158 \\
LATS1 & 16.71751549 & 15.69582851 & 13.40665365 & 30.11242179 & 33.83888394 & 32.42822804 & 0.000343 & 2.103438 \\
MOB1A & 15.38069089 & 13.32144837 & 12.64070767 & 25.61937594 & 24.69038453 & 23.12892559 & 0.000671 \\
NPHP4 & 22.87434157 & 20.0189737 & 22.36269368 & 14.94007595 & 11.31860782 & 10.97879836 & 0.005416 & 0.570637 \\
SAV1 & 5.321448365 & 6.658760605 & 6.548151196 & 25.79626637 & 25.40660827 & 25.39801236 & 0.000172 & 4.134251 \\
STK4 & 11.06159152 & 11.68175134 & 11.76547222 & 23.92575897 & 19.99353092 & 23.06959611 & 0.009991 & 1.941211 \\
WWC1 & 14.98695021 & 13.25237294 & 15.69304783 & 42.14629624 & 40.12990884 & 42.60605873 & 0.0000139 & 2.842602 \\
YAP & 18.8626 & 14.658 & 19.3661 & 2.59283 & 1.91762 & 1.76988 & 0.007723 & 0.118751 \\
YWHAE & 14.8928829 & 10.98269657 & 11.06684049 & 25.58243226 & 20.3183913 & 22.64409517 & 0.006653 & 1.855453 \\
\hline
\end{tabular}

AMOT, angiomotin; AMOTL1, angiomotin-like protein 1; AMOTL2, angiomotin-like protein 2; DVL2, dishevelled 2; LATS1, large tumor suppressor 1; MOB1A, MOB kinase activators 1A; NPHP4, nephrocystin-4; SAV1, salvador homolog-1; STK4, serine/threonine-protein kinase 4; WWC1, WW and C2 domain containing 1; YAP, yes-associated protein; YWHAE, 14-3-3 epsilon. 
Table S3 Gene Ontology (GO) analysis of significantly differentially expressed genes in control or degalactotigonin (DGT) treated 786-O cells

\begin{tabular}{|c|c|c|c|}
\hline Category & Term & \#-log10 (P value) & $P$ value \\
\hline GOTERM_BP_DIRECT & GO:0098609-cell-cell adhesion & 4.058356326 & $8.74 \mathrm{E}-05$ \\
\hline GOTERM_BP_DIRECT & GO:0008285-negative regulation of cell proliferation & 3.594999918 & $2.54 \mathrm{E}-04$ \\
\hline GOTERM_BP_DIRECT & GO:0006914-autophagy & 3.05960331 & $8.72 \mathrm{E}-04$ \\
\hline GOTERM_CC_DIRECT & GO:0005737-cytoplasm & 9.690401372 & $2.04 \mathrm{E}-10$ \\
\hline GOTERM_CC_DIRECT & GO:0005925-focal adhesion & 5.998075054 & $1.00 \mathrm{E}-06$ \\
\hline GOTERM_CC_DIRECT & GO:0005856-cytoskeleton & 4.60582154 & $2.48 \mathrm{E}-05$ \\
\hline GOTERM_CC_DIRECT & GO:0005913-cell-cell adherens junction & 4.27922899 & 5.26E-05 \\
\hline GOTERM_MF_DIRECT & GO:0005524-ATP binding & 4.37081345 & 4.26E-05 \\
\hline GOTERM_MF_DIRECT & GO:0019903-protein phosphatase binding & 4.178596409 & $6.63 \mathrm{E}-05$ \\
\hline GOTERM_MF_DIRECT & GO:0098641-cadherin binding involved in cell-cell adhesion & 4.117277804 & 7.63E-05 \\
\hline GOTERM_MF_DIRECT & GO:0004672-protein kinase activity & 3.925027976 & 1.19E-04 \\
\hline
\end{tabular}

$\mathrm{BP}$, biological process; CC, cellular component; MF, molecular function. 